\title{
A tool for assessing the accuracy of biometry
}

\author{
Lina Osman ${ }^{1} \cdot$ Yumna Busool Abu Eta ${ }^{1,2} \cdot$ Jeremy Prydal ${ }^{1}$
}

Received: 26 May 2019 / Accepted: 12 June 2019 / Published online: 18 July 2019

(c) The Royal College of Ophthalmologists 2019

Patient satisfaction and predictable refractive outcome in cataract surgery depends on accurate biometry and, as part of the validation process, it is advisable to ensure that any discrepancy in predicted intra-ocular lens (IOL) power between the two eyes is consistent with the difference in refraction [1].

We present here a spreadsheet developed for use in our local 'Complex Biometry Clinic', which accepts referrals where there is difficulty performing measurements or concern over their accuracy, including a significant discrepancy in lens power [2].

A $1 \mathrm{~mm}$ difference in axial length (AL) is known to result in $\sim 2.35$ dioptre (D) difference in refractive spherical equivalent, while a $1.0 \mathrm{D}$ difference in average keratometry $(\mathrm{K})$ equates to a $1.0 \mathrm{D}$ difference in refraction, if vertex distance is ignored. Also, a difference of 3.0D in predicted lens power tends to reflect a $2.0 \mathrm{D}$ difference in pre-cataract refraction [3]. Our software uses these values to evaluate biometric accuracy, giving a colour-coded outcome.

Biometric and refractive data are entered: axial length, keratometry, spectacle refraction and predicted IOL power for emmetropia. It is important to enter the oldest available 'pre-cataract' refraction, as asymmetrical index myopia can influence results. The software calculates the predicted difference in refraction given the $\mathrm{AL}$ and $\mathrm{K}$ readings and compares this with the actual difference in spectacle refraction. The expected difference in IOL power for a patient with this difference in refraction is then compared with calculated IOL values.

Jeremy Prydal

jeremy.prydal@uhl-tr.nhs.uk

1 Department of Ophthalmology, Leicester Royal Infirmary, University Hospitals of Leicester, Infirmary Square, Leicester LE1 5WW, UK

2 Department of Ophthalmology, the Saint Vincent de Paul hospital, faculty of medicine, Bar Ilan university, Ramat Gan, Israel
For display purposes a nominal colour-coded outcome is generated for each of the two values, with green indicating a difference of less than 1.0, yellow between 1.0 and 2.0 and red greater than 2.0 (Fig. 1). If both values are green (less than 1.0) it indicates that there is a close match between the refraction, biometric values and predicted lens power for each eye. Higher values indicate that further assessment is warranted.

Current NICE guidelines [4] do not discuss methods of assessing the accuracy of lens power calculations, although the earlier Royal College ones [5] included various criteria for repeating biometry. These defined limits for $\mathrm{AL}$ and $\mathrm{K}$ readings and for the maximal acceptable difference between eyes, advising repeat measurements if values lay outside the range. However, biometry may still be correct in such cases and in these situations our software offers a rapid and easy method for validating results.

In conclusion, the spreadsheet presented here provides a useful supplementary method for assessing the accuracy of biometry, particularly in cases of anisometropia where the predicted lens power differs between eyes.

\section{Compliance with ethical standards}

Conflict of interest The authors declare that they have no conflict of interest.

Publisher's note: Springer Nature remains neutral with regard to jurisdictional claims in published maps and institutional affiliations. 
Fig. 1 a a patient with $8.0 \mathrm{D}$ difference in IOL power accounted for by the difference in biometric values and consistent with refractive status, and $\mathbf{b}$ a patient with $2.5 \mathrm{D}$ difference in IOL power but probable error in biometric measurements

\section{a}

\begin{tabular}{|l|r|r|}
\multicolumn{3}{c}{ Right } \\
\hline AL & 29.75 & 32.54 \\
\hline K1 & 41.56 & 42.56 \\
\hline K2 & 47.54 & 45.92 \\
\hline
\end{tabular}

\begin{tabular}{|l|r|r|}
\hline Sphere & -15.50 & -21.25 \\
\hline Oldest refraction available
\end{tabular}

\begin{tabular}{|l|r|r|}
\hline Cyl & -6.00 & -6.00 \\
\hline
\end{tabular}

\begin{tabular}{|l|r|r|}
\hline IOL power & 2.0 & -6.0 IOL power for emmetropia \\
\hline
\end{tabular}

\begin{tabular}{|lr|}
\hline \multicolumn{2}{|c|}{$\Delta \mathrm{Ref}$ raction } \\
\hline Keratometry accounts for & $-0.31 \mathrm{R}>\mathrm{L}$ \\
AL accounts for & $6.56 \mathrm{R}>\mathrm{L}$ \\
Overall expected $\Delta$ refraction & $6.25 \mathrm{R}>\mathrm{L}$ \\
Actual $\Delta$ refraction & $5.75 \mathrm{R}>\mathrm{L}$ \\
\hline
\end{tabular}

\begin{tabular}{|ll|}
\hline \multicolumn{3}{|c|}{$\Delta \mathrm{IOL}$ P O wer } \\
\hline Expected $\triangle \mathrm{IOL}$ & $8.63 \mathrm{R}>\mathrm{L}$ \\
Actual $\triangle \mathrm{IOL}$ & $8.00 \mathrm{R}>\mathrm{L}$ \\
\hline
\end{tabular}

\begin{tabular}{|l|l|}
\hline $\begin{array}{l}\text { Biometry consistent } \\
\text { with refraction? }\end{array}$ & $\mathbf{0 . 5 0}$ \\
\hline $\begin{array}{l}\text { IOL powers consistent } \\
\text { with refraction? }\end{array}$ & $\mathbf{0 . 6 3}$ \\
\hline
\end{tabular}

b

\begin{tabular}{|l|r|r|}
\multicolumn{2}{c}{ Right } & \multicolumn{1}{c}{ Left } \\
\hline AL & 26.00 & 24.62 \\
\hline K1 & 41.82 & 42.40 \\
\hline K2 & 42.45 & 42.94 \\
\hline
\end{tabular}

\begin{tabular}{|l|r|r|}
\hline Sphere & -3.75 & -4.50 \\
\hline Cyl & -1.75 & -0.50 \\
\hline
\end{tabular}

\begin{tabular}{|l|r|r|}
\hline IOL power & 17.0 & 19.5 IOL power for emmetropia \\
\hline
\end{tabular}

\begin{tabular}{|lr|}
\hline \multicolumn{2}{|c|}{$\Delta R$ efraction } \\
\hline Keratometry accounts for & $0.53 R>L$ \\
AL accounts for & $-3.24 R>L$ \\
Overall expected $\Delta$ refraction & $-2.71 R>L$ \\
Actual $\Delta$ refraction & $0.13 R>L$ \\
\hline
\end{tabular}

\begin{tabular}{|lr|}
\hline \multicolumn{2}{|c|}{$\Delta \mathrm{IOL}$ P ower } \\
\hline Expected $\triangle \mathrm{IOL}$ & $0.19 \mathrm{R}>\mathrm{L}$ \\
Actual $\triangle \mathrm{IOL}$ & $-2.50 \mathrm{R}>\mathrm{L}$ \\
\hline
\end{tabular}

Actual $\triangle \mathrm{IOL}$

\begin{tabular}{|l|l|}
\hline $\begin{array}{l}\text { Biometry consistent } \\
\text { with refraction? }\end{array}$ & $\mathbf{2 . 8 3}$ \\
\hline $\begin{array}{l}\text { IOL powers consistent } \\
\text { with refraction? }\end{array}$ & $\mathbf{2 . 6 9}$ \\
\hline
\end{tabular}

\section{References}

1. Milind P. Refractive Surprise after Cataract Surgery. Royal College of Ophthalmologists Focus Autumn. 2010. P5-6. https://www.rcophth. ac.uk/wp-content/uploads/2014/08/Focus-Autumn-2010.pdf.

2. Hussain R, Rubinstein M, Mathew M, Ghosh S, Wakefield M, Savant V, et al. Complex biometry clinics: a new service development. Eye News. 2015;21. www.eyenews.uk.com.
3. Khurana AK. Intraocular lenses: optical aspects and power calculations. In: Theory and Practice of Optics and Refraction 2nd edn. (ed Nasim S.). Elsevier, 2008 pp 268.

4. Recommendations I Cataracts in adults: management | Guidance | NICE. 2017. https://www.nice.org.uk/guidance/ng77/chapter/ Recommendations\#preoperative-assessment-and-biometry.

5. The Royal College of Ophthalmologists Cataract Surgery Guidelines. 2010. www.rcophth.ac.uk. 